\title{
Produção de goma xantana obtida a partir do caldo de cana
}

\author{
Production of xanthan gum obtained from sugarcane
}

\section{Líllian Vasconcellos BRANDÃO ${ }^{1}$, Tatiana Barreto Rocha NERY ${ }^{1 \star}$, Bruna Aparecida Souza MACHADO³, Maria Cecília Azevedo ESPERIDIÃO ${ }^{2}$, Janice Izabel DRUZIAN ${ }^{3}$}

\section{Resumo}

Goma xantana é um heteroexopolissacarídeo sintetizado por Xanthomonas utilizando glicose ou sacarose como fontes de carbono, além de outros micronutrientes. É de grande aplicação industrial, devido às suas propriedades reológicas. O caldo de cana é rico em nutrientes, podendo ser utilizado como substrato para obtenção de xantana, viabilizando a produção no País pela redução dos custos. O objetivo deste estudo foi testar a produção da xantana obtida com diferentes cepas nativas de Xanthomonas em meio de cultivo composto de caldo de cana (XCC) e compará-la com os valores obtidos com a sacarose (XS). Foram preparados meios com o mínimo dos requerimentos nutricionais, contendo sacarose ou caldo de cana, suplementados apenas com uréia $(0,01 \%)$ e fosfato $(0,1 \%)$, fermentados em shaker $\left(28^{\circ} \mathrm{C}, 250 \mathrm{rpm}, 120 \mathrm{horas}\right)$. A maior produção de xantana foi obtida com a Xanthomonas campestris manihotis e caldo de cana $\left(33,54 \mathrm{~g} . \mathrm{L}^{-1}\right)$, valor aproximadamente dez vezes maior que o obtido com a sacarose $\left(3,45\right.$ g. $\left.\mathrm{L}^{-1}\right)$. A viscosidade aparente a $25 \mathrm{~s}^{-1}, 2,0 \%$ de goma e $25^{\circ} \mathrm{C}$ foi de $99,36 \mathrm{mPa} . \mathrm{s}$ para XCC e de 500,43 mPa.s para XS. A biossíntese da xantana a partir do caldo de cana merece peculiar atenção, constituindo-se numa possibilidade promissora para sua produção em larga escala.

Palavras-chave: goma xantana; biopolímero; caldo de cana; Xanthomonas campestris.

\begin{abstract}
The xanthan gum is a heteroexopolysaccharide synthesized by Xanthomonas campestris in a culture medium using glucose or sucrose as carbon sources and other nutrients. Due to its rheological properties, it has been contributing for the range of applications in the food industry, pharmaceutical, and tertiary recovery of oil. Sugarcane is rich in nutrients (sugars and minerals) and can be used as a substratum for the xanthan production, which can be produced in Brazil due to its cost reduction. The objective of this study was to test the production of the xantana obtained with different culture native of Xanthomonas in medium composed of sugarcane broth (XSC) and to compare with the values obtained with sucrose (XS). Two medium cultures were used with the minimum of the nutrients, contained sucrose or sugar cane complemented with urea $(0.01 \%)$ and $\mathrm{K}_{2} \mathrm{HPO}_{4}(0.1 \%)$, fermented in shaker $\left(28^{\circ} \mathrm{C}, 250 \mathrm{rpm}, 120\right.$ hours). The best production was obtained using Xanthomonas campetris manihotis and sugarcane ( $\left.33.54 \mathrm{~g} . \mathrm{L}^{-1}\right)$, approximately ten times bigger then obtained with the sucrose (3.45 g. $\mathrm{L}^{-1}$ ). The apparent viscosity for an aqueous solution of $2.0 \%$ of gum to $25^{\circ} \mathrm{C}$ and $25 \mathrm{~s}^{-1}$ was $99.36 \mathrm{mPa} . \mathrm{s}$ for XSC and $500.43 \mathrm{mPa}$.s to XS. The biosynthesis of xanthan starting from sugarcane deserves peculiar attention, constituting like this, a promising possibility for gum production in wide climbs.
\end{abstract}

Keywords: xanthan gum; biopolymer; sugarcane; Xanthomonas campestris.

\section{Introdução}

Biopolímeros são polissacarídeos de origem microbiana, sintetizados por bactérias, fungos e leveduras. Xantanas são exopolissacarídeos (EPS), que possuem a capacidade de formar géis e soluções viscosas em meio aquoso (MEDEIROS et al. 2000). Apresentam-se como uma alternativa às gomas tradicionais devido às suas propriedades reológicas, sendo amplamente utilizadas como espessantes, geleificantes, agentes de suspensão, colóides protetores e estabilizantes, nas indústrias de alimentos, farmacêutica, química e petroquímica (FARIA, 2005; LIMA et al., 2001).

A goma xantana é um biopolímero classificado como heteroexopolissacarídeo ramificado, aniônico, produzido por fermentação, empregando a bactéria Xanthomonas campestris.
Essas bactérias apresentam células em forma de bastonetes, Gram-negativas e ocorrem predominantemente isoladas (GARCÍA-OCHOA et al., 2000).

Os polissacarídeos extracelulares apresentam maior interesse industrial, devido à maior facilidade de extração e purificação, e por não sofrerem influências sazonais (MARCOTTE; TAHERIAN; RAMASWAMY, 2001). Segundo Foresti (2003), atualmente a xantana é o polissacarídeo com maior estabilidade entre os existentes no mercado, por formar soluções aquosas de alta viscosidade, extremamente pseudoplásticas. A viscosidade, que pode ser tomada como parâmetro de qualidade, é influenciada pelo tipo das cepas, composição do meio de fermentação e pelas condições operacionais utilizadas na produção.

Recebido para publicação em 6/6/2007

Aceito para publicação em 18/5/2008 (002582)

${ }^{1}$ Departamento de Engenharia Química, Universidade Federal da Bahia - UFBA, CEP 40210-630, Salvador - BA, Brasil, E-mail: tatianabr@ufba.br

${ }^{2}$ Departamento de Química, Universidade Federal da Bahia - UFBA, CEP 40170-115, Salvador - BA, Brasil

${ }^{3}$ Departamento de Análises Bromatológicas, Universidade Federal da Bahia - UFBA, CEP 40171-970, Salvador - BA, Brasil

${ }^{*}$ A quem a correspondência deve ser enviada 
O Brasil é o maior produtor de cana-de-açúcar do mundo, responsável por $25 \%$ da produção mundial, sendo $60 \%$ dela produzida no Estado de São Paulo (FARIA, 2005). Considerando a riqueza nutricional do caldo de cana (sacarose, glicose, frutose, fibra, celulose, minerais e demais micronutrientes), este pode ser usado como um meio de cultivo para as bactérias de Xanthomonas bioconverterem estes nutrientes em goma xantana, produto de alto valor agregado e totalmente importado pelo Brasil, viabilizando assim a produção no País pela redução dos custos.

Considerando o exposto, este trabalho teve como objetivo avaliar a produção e alguns parâmetros físicos dos exopolissacarídeos de goma xantana obtidos a partir de linhagens nativas de Xanthomonas campestris em meio fermentativo composto de caldo de cana, em função das variações de concentração das soluções, da temperatura e da taxa de cisalhamento aplicadas e compará-los com os valores obtidos pela bioconversão em meio composto por sacarose.

\section{Material e métodos}

As linhagens nativas utilizadas foram Xanthomonas campestris manihotis 1182, Xanthomonas campestris campestris 1866 e Xanthomonas campestris pv campestris 2149. As cepas foram doadas da coleção de culturas de fitobactérias do Instituto Biológico - IBSBF, Campinas-SP. As culturas foram mantidas em YM-agar inclinado, sob refrigeração e repicadas periodicamente. As etapas de obtenção de goma foram: inóculo; cultivo; e recuperação da goma.

O caldo de cana utilizado foi coletado dos pontos de comercialização da cidade de Salvador - BA. Após recebimento, o caldo foi filtrado e imediatamente congelado, em volumes de $500 \mathrm{~mL}$ e mantido a $-5^{\circ} \mathrm{C}$.

\subsection{Composição do caldo de cana utilizado na fermentação}

O teor de umidade, proteína bruta, lipídios totais, cinzas e carboidratos foram determinados segundo metolodogia da AOAC (1997).

\subsection{Repicagem e inoculação}

Para o processo de repicagem utilizou-se o meio YM agar (sólido), acrescentando agar puríssimo $(2,0 \%)$ ao meio YM padrão. $\mathrm{O}$ volume de $10 \mathrm{~mL}$ do meio foi transferido para tubos de ensaio e autoclavados a $121^{\circ} \mathrm{C}$ por 15 minutos. A repicagem foi realizada com uma alçada das culturas mantidas em estoque e incubadas em estufa por 48 horas a $28^{\circ} \mathrm{C}$.

Para a preparação do inóculo, foi utilizado o meio YM padrão (Yeast-Malt) líquido, contendo 1,0\% de glicose; 0,5\% de peptona bacteriológica; $0,3 \%$ de extrato de levedura; $0,3 \%$ de extrato de malte em água destilada (p/v) (CASAS; SANTOS; GARCÍA-OCHOA, 2000). O volume de $50 \mathrm{~mL}$ do meio YM foi autoclavado $\left(121^{\circ} \mathrm{C} / 15\right.$ minutos) em Erlemeyer de $250 \mathrm{~mL}$, esfriado, inoculado com uma alçada da cultura de Xanthomonas e incubado a $28^{\circ} \mathrm{C}$ sob agitação de $150 \mathrm{rpm}$ por 48 horas.

\subsection{Produção de goma xantana}

A produção de goma xantana foi realizada em meio fermentativo composto com um mínimo de nutrientes necessários de acordo com citações de Druzian e Pagliarini (2007), buscando obter um meio alternativo de baixo custo. Portanto, utilizou-se uma fonte de Nitrogênio, uma de Fósforo e uma de Carbono, que são os requerimentos nutricionais mínimos para a Xanthomonas produzir goma xantana. $\mathrm{O}$ meio convencional foi composto de sacarose (2\%) acrescido de $0,01 \%$ de Uréia e $0,1 \%$ de $\mathrm{K}_{2} \mathrm{HPO}_{4}$. No meio alternativo, a sacarose (fonte de carbono) foi substituída por caldo de cana (substrato alternativo), ou seja, o caldo de cana integral foi acrescido de $0,01 \%$ de Uréia e de $0,1 \%$ de $\mathrm{K}_{2} \mathrm{HPO}_{4}$. Os meios foram ajustados para $\mathrm{pH}=7,0$ e autoclavados a $121^{\circ} \mathrm{C}$ por 15 minutos.

Foram transferidos $16 \mathrm{~mL}$ do inóculo para Erlemeyer de $250 \mathrm{~mL}$ contendo $80 \mathrm{~mL}$ do meio padrão (sacarose) ou do meio alternativo (caldo de cana). O cultivo em batelada foi realizado em incubadora rotatória Tecnal com agitação de $250 \mathrm{rpm}$ a $28^{\circ} \mathrm{C}$ por 120 horas.

\subsection{Recuperação e purificação da goma}

Para a separação de goma xantana produzida, foi adicionado álcool etílico ao produto fermentado na proporção de 3 partes de álcool para 1 parte do meio fermentativo. A goma precipitada foi retirada com o auxílio de um bastão de vidro e transferida para placas de Petri, previamente taradas, secada em estufa $\left(30 \pm 2{ }^{\circ} \mathrm{C}\right)$ por 72 horas, moída e armazenada.

$\mathrm{O}$ rendimento de goma xantana por litro de meio fermentativo utilizado foi medido por gravimetria. $\mathrm{O}$ rendimento da produção obtida variando-se as cepas foi calculado e os valores expressos em g.L $\mathrm{L}^{-1}$ (g de goma por litro de meio de cultivo).

\subsection{Viscosidade aparente}

A viscosidade aparente em função da taxa de cisalhamento foi calculada a partir da tensão de cisalhamento medida em taxas de cisalhamento pré-fixadas. A tensão e a taxa de cisalhamento foram medidas em um reômetro rotacional da Haake modelo Rheotest 2.1, com sistema de medida constituído de uma mola helicoidal cilíndrica e dispositivo de cilindros concêntricos tipo S1 (relação entre os raios dos cilindros interno, $r$, e externo, $R$, $\mathrm{r} / \mathrm{R}=0,98$ ), acoplado a um banho termostático da marca Lauda com precisão de medida de temperatura de $\pm 0,01{ }^{\circ} \mathrm{C}$. Foram requeridos, para esse modelo de reômetro, $25 \mathrm{~mL}$ das soluções de goma xantana. As viscosidades aparentes de soluções aquosas da goma foram determinadas nos intervalos de concentração entre 0,5 e $2,0 \%$, nas temperaturas de $25,45,65$ e $85^{\circ} \mathrm{C}$ e taxas de cisalhamento entre $25 \mathrm{e} 1000 \mathrm{~s}^{-1}$. As soluções aquosas foram preparadas e permaneceram em repouso por 12 horas à temperatura ambiente antes de se realizarem as medidas. A amostra foi transferida para o cilindro externo e a velocidade de rotação do cilindro interno, imerso na solução, foi mantida constante em cada medida, e posteriormente, variada de quantidades pré-estabelecidas no aparelho, resultando nas diferentes taxas de cisalhamento. As correspondentes tensões de cisalhamento foram determinadas convertendo-se as leituras feitas, usandose um amperímetro, em valores em Pascal. A dependência da 
viscosidade das soluções de goma xantana com a taxa de cisalhamento pode ser descrita pelo modelo cinético de Ostwald-de Waele ou lei da potência (CHHABRA; RICHARDSON, 1999) segundo a Equação 1:

$\mu \alpha=\frac{\tau}{\gamma}=K(\gamma)^{n-1}$

onde, $K$ é o índice de consistência; $n$ é o índice do comportamento do fluxo; $\mu \alpha$ é a viscosidade aparente; $\tau$ é a tensão cisalhante; e $\gamma$ é a taxa de cisalhamento.

\section{Resultados e discussão}

Os resultados da composição centesimal do caldo de cana estão expostos na Tabela 1. O caldo de cana utilizado no processo fermentativo para produção de goma xantana apresentou $81,00 \%$ de umidade e $19,00 \%$ de matéria seca, dos quais $16,52 \%$ são carboidratos. $\mathrm{O}$ valor de proteínas apresentado ficou em torno de $1,55 \%$ e, para as cinzas, um valor de $0,19 \%$. Estes compostos são de grande importância considerando sua utilização como substratos na fermentação pelas bactérias Xanthomonas, uma vez que irão fazer parte dos nutrientes tanto para o crescimento celular como para a biossíntese de goma xantana.

Segundo Sutherland (1982), uma elevada concentração de nitrogênio é necessária para um rápido crescimento celular, entretanto, quando a concentração de nitrogênio no meio de cultura é muito elevada, a goma xantana produzida normalmente apresenta viscosidade aparente baixa. Meios contendo elevado teor de carbono e baixo teor de nitrogênio favorece o acúmulo de polímero. A relação C:N para o caldo de cana foi de aproximadamente 10:1 (Tabela 1). Em geral, os processos industriais procuram utilizar meios que disponibilizem condições tanto para o crescimento como para o acúmulo de goma (VASHITZ; SHEINTUCH, 1991).

Segundo Faria (2005), a cana de açúcar é rica em carboidratos (sacarose, glicose e frutose) que equivale a aproximadamente $20 \%$, enquanto que os $80 \%$ restantes contêm água (maior quantidade) e minerais. O caldo de cana, como subproduto da cana de açúcar, pode ser usado como substrato em processos fermentativos agregando valor ao produto.

\subsection{Produção do biopolímero}

O melhor resultado da produção de goma xantana foi obtido pelo microrganismo Xanthomonas campestris manihotis 1182, utilizando o meio de cultivo alternativo constituído por uréia, $\mathrm{K}_{2} \mathrm{HPO}_{4}$ e caldo de cana, apresentando uma produção

Tabela 1. Valor médio da composição centesimal do caldo de cana utilizado na fermentação para obtenção de goma xantana.

\begin{tabular}{lc}
\hline \multicolumn{1}{c}{ Análises } & Composição (\%) \\
\hline Umidade & $81,00 \pm 0,1$ \\
Cinzas & $0,19 \pm 0,1$ \\
Lipídios totais & $0,74 \pm 0,1$ \\
Proteína bruta & $1,55 \pm 0,1$ \\
Carboidratos & $16,52 \pm 0,1$ \\
\hline
\end{tabular}

de $33,54 \pm 0,10$ g.L $L^{-1}$ (Tabela 2 ) com produtividade média de $0,28 \pm 0,10 \mathrm{~g} \cdot \mathrm{L}^{-1} \cdot \mathrm{h}^{-1}$.

O rendimento médio da produção de goma xantana no meio alternativo contendo caldo de cana como substrato, dependendo da cepa utilizada, apresentou um aumento da ordem de 4 a 10 vezes na produção, quando comparada com os valores obtidos no meio convencional contendo sacarose (Tabela 2).

Dentre os poucos estudos utilizando caldo de cana como substrato alternativo na produção de xantana, todos apresentaram valores menores ou no máximo iguais de rendimento. A produção de 7,48 g.L. $\mathrm{L}^{-1}$ de goma xantana em 48 horas a $120 \mathrm{rpm}$ e $28{ }^{\circ} \mathrm{C}$ foi obtida por Araújo et al. (2005), e de 15,1 g. $L^{-1}$ de goma xantana em 30 horas a $800 \mathrm{rpm} \mathrm{e} 28^{\circ} \mathrm{C}$, por Faria (2005). Em ambos, foi utilizada a cepa $X$. campestris $p v$. campestris NRRL B-1459 e caldo de cana. El-Salam et al. (1994) obtiveram 11,5 g. $L^{-1}$ de goma xantana em 72 horas de incubação a $30^{\circ} \mathrm{C}$ usando $X$. campestris E-NRC-3 e melaço de cana de açúcar.

\subsection{Comparativo do comportamento reológico da xantana obtida com sacarose e com caldo de cana}

De acordo com os resultados da Tabela 2, pode-se observar que os maiores rendimentos de goma xantana (g.L $\left.\mathrm{L}^{-1}\right)$ foram obtidos quando se utilizou a cepa Xanthomonas campestris manihotis 1182. Esta goma foi selecionada para estudo do perfil de viscosidade em diferentes tensões de cisalhamento, temperaturas e concentração. Foram realizados estudos comparativos entre o comportamento reológico das soluções aquosas das gomas obtidas com o substrato alternativo e os reogramas da goma xantana produzida com sacarose como fonte de carbono.

Pode-se observar na Figura 1 que, para todas as temperaturas e soluções aquosas de 1,0\% a 2,0\%, a viscosidade da goma obtida com o caldo de cana apresentou valores inferiores à obtida com a sacarose (Figura 2); resultados evidenciados em baixas taxas de cisalhamento. Este fato sugere que a goma produzida com sacarose apresenta melhor propriedade reológica, ou seja, maior viscosidade gerada por unidade de polímero produzido. A diferença maior foi observada nas soluções com concentração de 2,0\% nas quais essa diferença foi de aproximadamente cinco vezes.

Portanto, apesar do rendimento de goma obtida a partir do caldo de cana ter sido aproximadamente dez vezes maior do que os valores obtidos com sacarose (Tabela 2), a viscosidade aparente foi muito inferior à obtida com o meio contendo a fonte de carbono convencional (Figura 1), ou seja, uma cepa com alta produtividade de goma, entretanto com viscosidade aparente muito menor. Uma alternativa é utilizar a goma obtida com caldo de cana em uma concentração maior.

\subsection{Efeito da concentração sobre o comportamento reológico}

A $25^{\circ} \mathrm{C}$, o aumento da concentração da solução de goma xantana, para o meio a partir da sacarose e para o meio alternativo a partir da cana de açúcar, provocou aumento na viscosidade, no intervalo de taxas de cisalhamento entre 25 e $1000 \mathrm{~s}^{-1}$ (Figura 1 e 2); resultados que estão de acordo com os obtidos por Sutherland (2002). De acordo com análises de regressão, 
a viscosidade aumentou exponencialmente com o aumento da concentração de xantana, (Figura 1 e 2).

A principal característica exibida pela goma xantana é a habilidade de modificar o comportamento reológico das suas soluções, dependendo principalmente da composição química, arranjos e/ ou ligações moleculares e peso molecular médio do polímero (MILAS; RINAUDO, 1986). Segundo Sutherland (2002), a goma xantana forma soluções viscosas a baixas taxas de concentração $(0,05-1 \%)$ e possui ampla faixa de estabilidade a $\mathrm{pH}$ e temperatura. $\mathrm{O}$ efeito de diferentes concentrações da goma $(0,5-2,0 \%)$ sobre a viscosidade a várias temperaturas é mostrado na Figura 3.

Os parâmetros que caracterizam o comportamento pseudoplástico $(n<1)$ do biopolímero obtido, bem como o índice de consistência do polímero $(K)$ são mostrados na Tabela 3. Foi realizado o ajuste do modelo de Ostwald-de Waele aos dados experimentais, a partir da regressão de potência.

O índice da consistência $(K)$ aumenta com o aumento da concentração de goma xantana (Tabela 3). Este efeito foi relatado também por Xuewu et al. (1996). Ahmed e Ramaswamy (2003) e Marcotte et al. (2001) relataram que com o aumento da concentração das soluções de goma xantana ocorre simultaneamente o decréscimo nos valores do índice de fluxo $(n)$. A variação da concentração de polissacarídeo em solução afeta diretamente a viscosidade e o grau de pseudoplasticidade (SUTHERLAND, 1996).

\subsection{Efeito da temperatura na viscosidade aparente}

$\mathrm{O}$ efeito de diferentes temperaturas $\left(25,45,65\right.$ e $\left.85^{\circ} \mathrm{C}\right)$ sobre a viscosidade de soluções aquosas da goma obtida com caldo de cana é mostrado na Figura 4. A viscosidade da goma xantana obtida pela bioconversão do caldo de cana aumenta como o aumento da concentração e diminui com o aumento da temperatura no intervalo entre 25 e $85^{\circ} \mathrm{C}$.

O índice da consistência $(K)$ diminui com o aumento de temperatura e o índice de fluxo aumenta com o aumento da temperatura (Tabela 3$)$. Na mais baixa concentração $(0,50 \%)$ e mais alta temperatura $\left(85^{\circ} \mathrm{C}\right)$, o valor de $n$ aproxima-se de 1 que representa o comportamento Newtoniano. Na mais alta concentração, o valor de $n$ é em torno de 0,5.

O decréscimo da viscosidade com o aumento da temperatura está associado às mudanças da conformação das moléculas de xantana decorrentes da elevação da temperatura (MILAS; RINAUDO, 1979). Soluções de xantana sofrem uma transição de conformação de uma estrutura ordenada, rígida, para um emaranhado desordenado ao serem aquecidas acima do ponto de derretimento (MEDEIROS et al., 2000).
Os grupos acetil e piruvil, presentes na estrutura do biopolímero, têm uma influência notável na conformação estrutural. Segundo Sutherland (1996), os grupos acetil estabilizam a forma ordenada, enquanto que o grupo piruvato causa o efeito oposto.

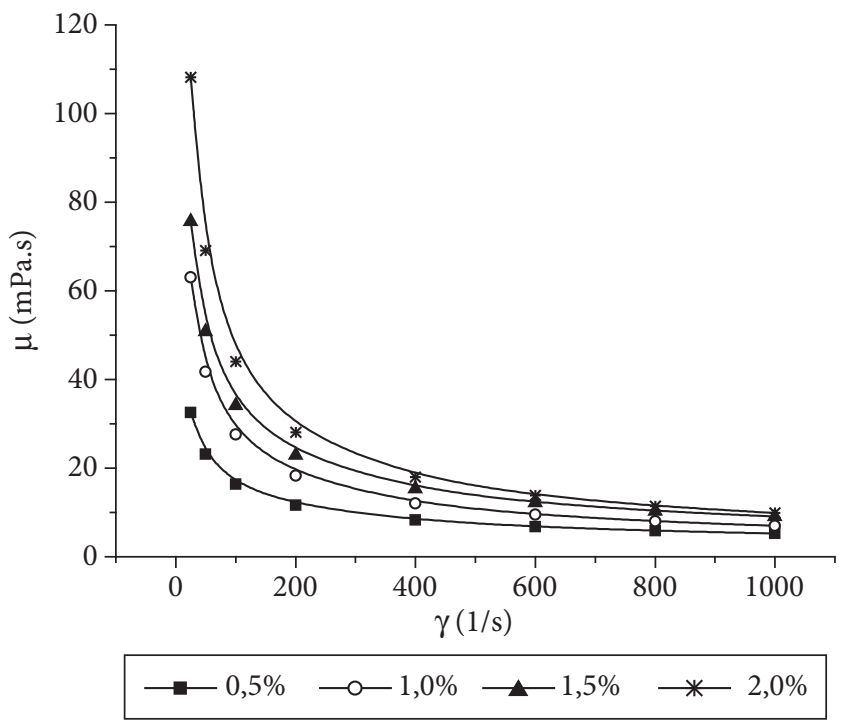

Figura 1. Viscosidade aparente a $25^{\circ} \mathrm{C}$ da goma xantana sintetizada pela cepa Xanthomonas campestris manihotis 1182 utilizando caldo de cana como substrato na fermentação a várias concentrações.

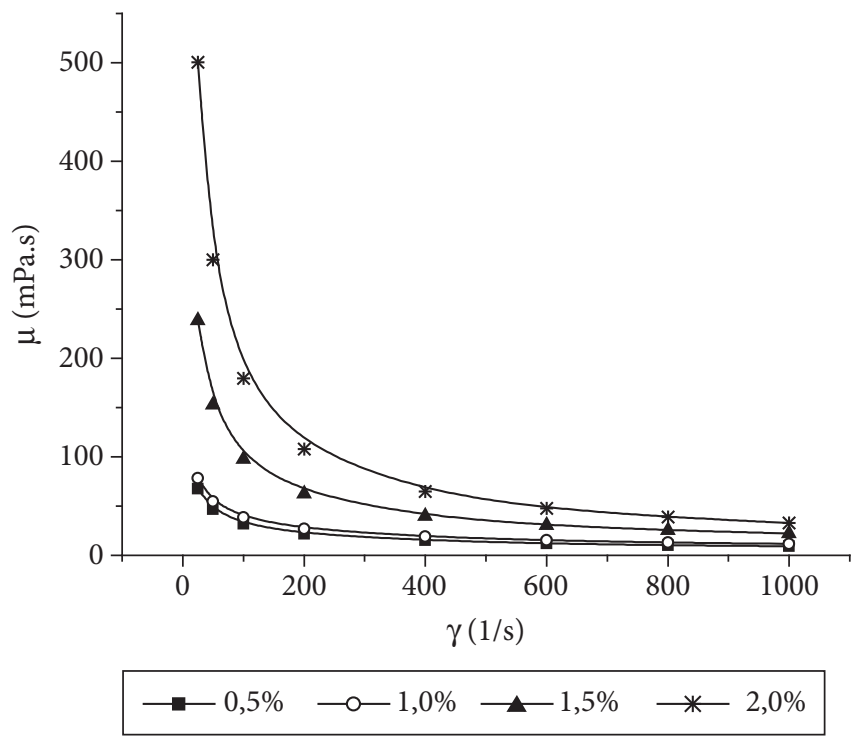

Figura 2. Viscosidade aparente a $25^{\circ} \mathrm{C}$ da goma xantana sintetizada pela cepa Xanthomonas campestris manihotis 1182 utilizando sacarose como substrato na fermentação a várias concentrações.

Tabela 2. Valores médios dos resultados da produção de goma, obtidos em meio de cultivo padrão e alternativo sintetizados por diferentes cepas nativas de Xanthomonas campestris.

\begin{tabular}{lccc}
\hline Meios de cultivo & \multicolumn{3}{c}{ Cepas } \\
\cline { 2 - 4 } & Xanthomonas campestris manihotis 1182 & Xanthomonas campestris campestris 1866 & Xanthomonas campestris pv campestris 2149 \\
\cline { 2 - 4 } & $3,45 \pm 0,1$ & Valores médios da produção de goma (g. $\mathrm{L}^{-1}$ ) & \\
\hline Convencional & $3,17 \pm 0,2$ & $4,02 \pm 0,2$ \\
Alternativo & $33,54 \pm 0,1$ & $14,23 \pm 0,3$ & $17,93 \pm 0,3$ \\
\hline
\end{tabular}



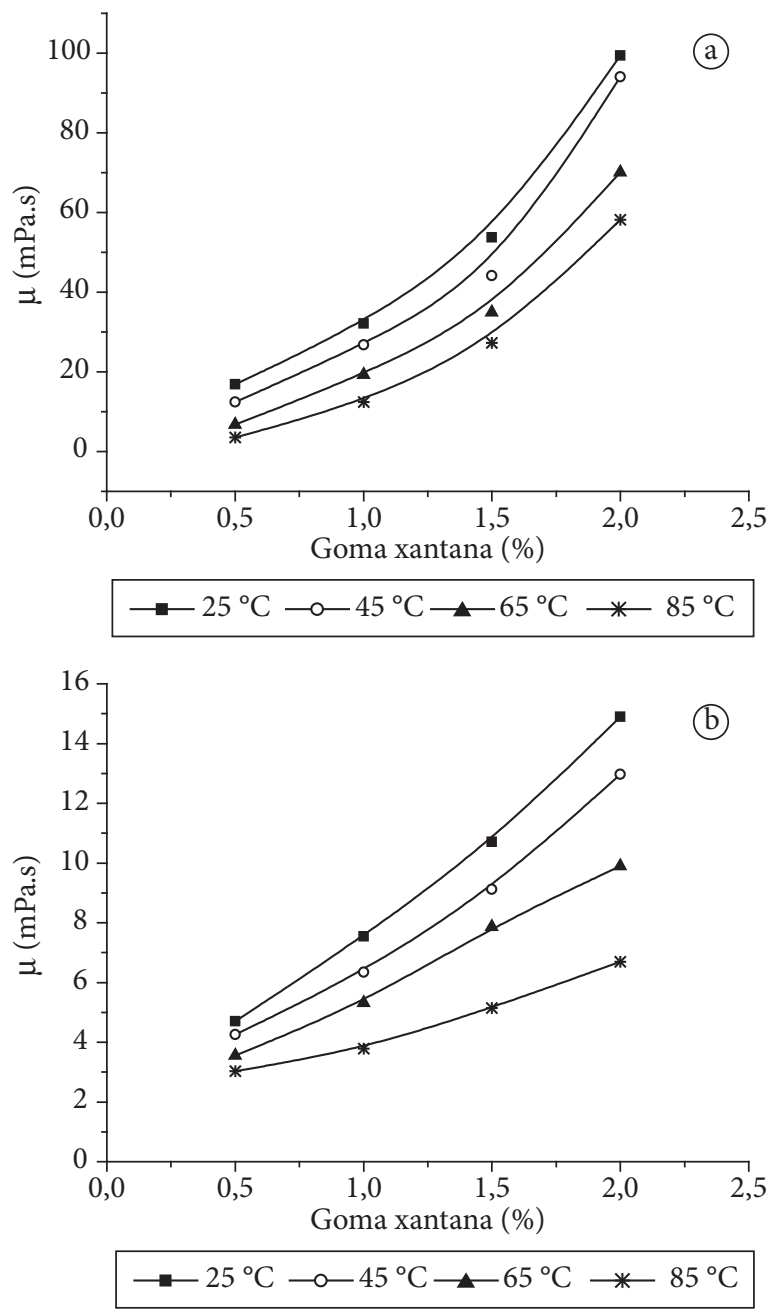

Figura 3. Viscosidade aparente (mPa.s) da goma xantana obtida a partir do caldo de cana, sintetizada pela cepa Xanthomonas campestris manihotis 1182 em diferentes concentrações e temperaturas nas taxas de cisalhamento de a) $25 \mathrm{~s}^{-1}$; e b) $1000 \mathrm{~s}^{-1}$.

Tabela 3. Parâmetros reológicos que caracterizam a pseudoplasticidade do biopolímero sintetizado pela cepa Xanthomonas campestris manihotis 1182 utilizando caldo de cana como substrato.

\begin{tabular}{lcccc}
\hline & \multicolumn{5}{c}{ Goma xantana } \\
\cline { 2 - 5 } $\mathrm{T}\left({ }^{\circ} \mathrm{C}\right)$ & $0,50 \%$ & $1,00 \%$ & $1,50 \%$ & $2,00 \%$ \\
25 & 0,653 & 0,607 & 0,562 & 0,486 \\
45 & 0,709 & 0,609 & 0,573 & 0,463 \\
65 & 0,825 & 0,651 & 0,595 & 0,459 \\
85 & 0,958 & 0,672 & 0,548 & 0,370 \\
$\mathrm{~T}\left({ }^{\circ} \mathrm{C}\right)$ & \multicolumn{5}{c}{$K$} \\
25 & 51,71 & 114,02 & 219,82 & 520,35 \\
45 & 31,73 & 94,12 & 174,74 & 529,71 \\
65 & 11,94 & 59,18 & 128,68 & 399,25 \\
85 & 4,03 & 35,28 & 116,72 & 441,74 \\
$\mathrm{~T}\left({ }^{\circ} \mathrm{C}\right)$ & \multicolumn{5}{c}{$\mathrm{R}^{2}$} \\
25 & 0,993 & 0,997 & 0,999 & 0,997 \\
45 & 0,998 & 0,999 & 0,996 & 0,999 \\
65 & 0,984 & 0,996 & 0,999 & 0,997 \\
85 & 0,971 & 0,995 & 0,988 & 0,966 \\
\hline
\end{tabular}
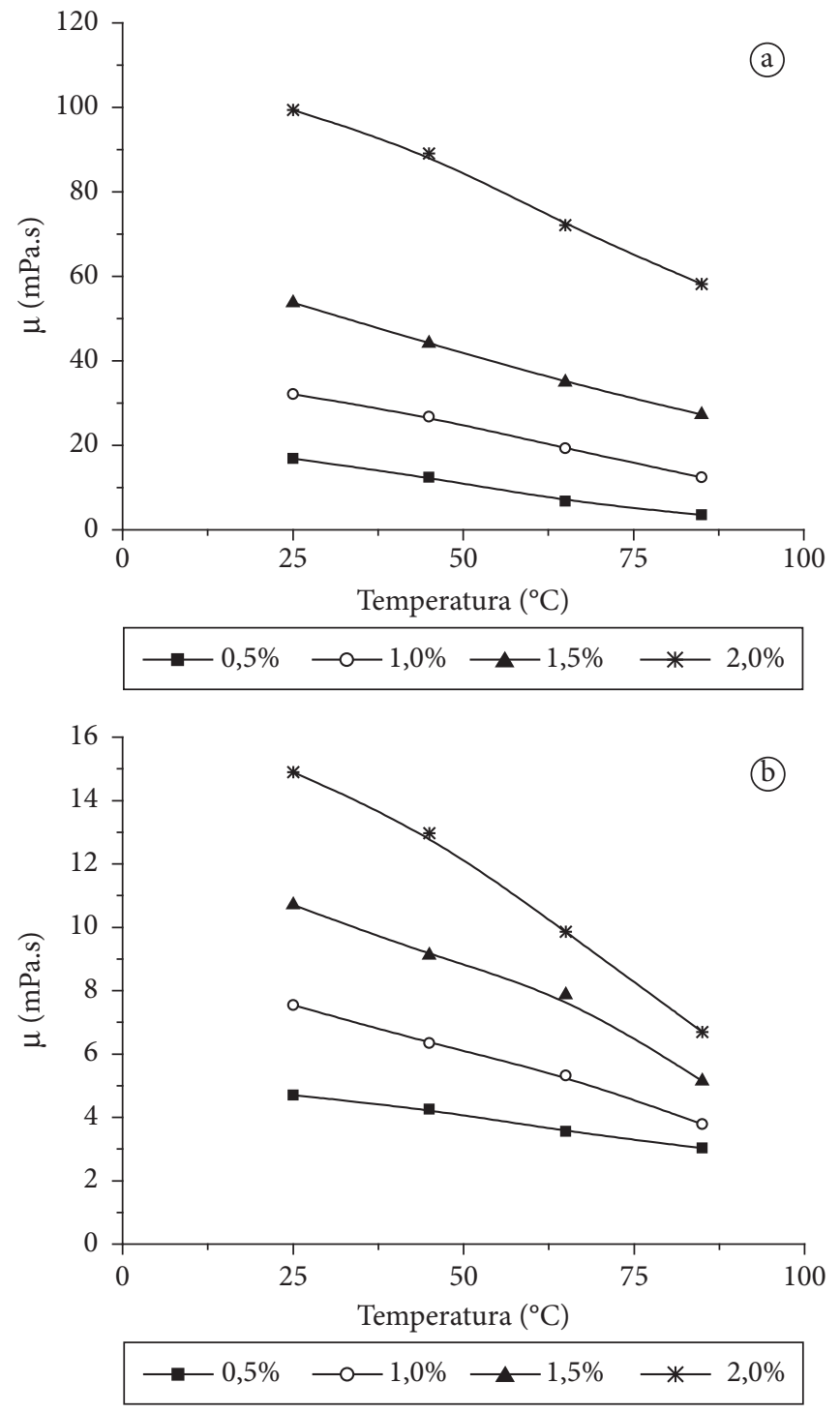

Figura 4. Viscosidade aparente (mPa.s) da goma xantana obtida a partir do caldo de cana, sintetizada pela cepa Xanthomonas campestris manihotis 1182 em diferentes temperaturas na taxa de cisalhamento de a) $25 \mathrm{~s}^{-1}$; e b) $1000 \mathrm{~s}^{-1}$.

\section{Conclusões}

É possível produzir goma xantana com as cepas nativas de Xanthomonas campestris manihotis 1182, Xanthomonas campestris campestris 1866 e Xanthomonas campestris pv campestris 2149 em meio fermentativo composto de caldo de cana suplementado com $0,01 \%$ de uréia e $0,1 \%$ de $\mathrm{K}_{2} \mathrm{HPO}_{4}$ a $28{ }^{\circ} \mathrm{C}, 250 \mathrm{rpm}$ por 120 horas de fermentação. A produção máxima de goma xantana foi de 33,54 g.L $\mathrm{L}^{-1}$ utilizando caldo de cana e a cepa 1182; rendimento 10 vezes maior do que o obtido com sacarose. As gomas xantana produzidas apresentaram comportamento reológico pseudoplástico característico de soluções de goma xantana, com viscosidade aparente de 99,36 mPa.s (solução a 2,0\% e $25 \mathrm{~s}^{-1}$ ) para a goma obtida com caldo de cana, valor cinco vezes menor do que o da goma obtida com sacarose. Considerando a alta produção e a baixa 
viscosidade aparente da goma xantana obtida com caldo de cana como substrato fermentativo quando comparada à goma obtida com a sacarose, outros testes podem ser aplicados para otimização do processo fermentativo, principalmente meios contendo outros micronutrientes.

\section{Referências bibliográficas}

AHMED, J.; RAMASWAMY, H. S. Effect of high-hydrostatic pressure and concentration on rheological characteristics of xanthan gum. Food Hydrocolloids, v. 18, n. 3, p. 367-373, 2003.

ARAÚJO, T. A. et al. Avaliação do comportamento reológico dos diferentes meios de produção de goma xantana a partir do caldo de cana. In: Congresso Brasileiro de Engenharia Química em Iniciação Científica, 6, 2005, Campinas. Anais... Campinas, 2005.

CASAS, J. A.; SANTOS, V. E.; GARCÍA-OCHOA, F. Xanthan gum production under several operational conditions: molecular structure and rheological properties. Enzyme and Microbial Technology, v. 26, n. 2-4, p. 282-291, 2000.

CHHABRA, R. P.; RICHARDSON, J. F. Non-newtonian flow in the process industries fundamentals and engineering applications. Great Britain: Butterworth Heinemann, 1999. 436 p.

DRUZIAN J. I; PAGLIARINI A. P. Produção de goma xantana por fermentação do resíduo de suco de maçã. Ciência e Tecnologia de Alimentos, v. 27, n. 1, p. 26-31, jan.-mar. 2007.

EL-SALAM, M. H. A.; FADEL, M. A.; MURAD, H. A. Bioconversion of sugarcane molasses into xanthan gum. Journal of Biotechnology, v. 33, n. 1, p. 103-106, 1994.

FARIA, S. Produção de goma xantana empregando caldo de cana por Xanthomonas campestris pv campestris NRRL B-1459. Uberlândia, 2005. 119 f. Dissertação - (Mestrado em Engenharia Química), Curso de Pós-graduação em Engenharia Química, Universidade Federal de Uberlândia.

FORESTI, A. P. Produção e qualidade reológica da xantana sintetizada por diferentes cepas de Xanthomonas campestris em meios modificados. Pelotas, 2003. 61 f. Dissertação - (Mestrado em Ciência e Tecnologia Agroindustrial), Pós-graduação em Agronomia, Universidade Federal de Pelotas.
GARCÍA-OCHOA, F. et al. Xanthan gum: production, recovery, and properties. Biotechnology Advances, v. 18, n. 7, p. 549-579, 2000.

AOAC (Association of Official Analytical Chemistis). Official Methods of Analysis of AOAC International. 16th ed., Horwitz, W. (ed.), Gaithersburg, Maryland, USA, 1997.

LIMA, U. A. et al. Biotecnologia industrial: processos fermentativos e enzimáticos. São Paulo: Edgard Blucher Ltda., 2001. v. 3, p. 125-154.

MARCOTTE, M.; TAHERIAN, A. R.; RAMASWAMY, H. S. Rheological properties of selected hydrocolloids as a function of concentration and temperature. Food Research International, v. 34, n. 8 , p. $695-703,2001$.

MEDEIROS, I. S. et al. Influência do método de recuperação e purificação de xantana produzida por Xanthomonas campestris pv. pruni cepa 06. In Congresso Brasileiro de Ciência e Tecnologia de Alimentos, 17, 2000, Fortaleza. Anais... Fortaleza, v. 3, p. 9-29, 2000

MILAS, M.; RINAUDO, M. Conformational investigation on the bacterial polysaccharide xanthan. Carbohydrate Research, v. 76, n. 1, p. 189-96, 1979.

. Properties of xanthan gum in aqueous solutions: role of the conformational transition. Carbohydrate Research, v. 158, p. 191-204, 1986.

SUTHERLAND, I. W. A sticky business. Microbial polysaccharides: current products and future trends. Microbiology Today, v. 29, p. 70-71, 2002.

Biosynthesis of microbial exopolysaccharides. Advances in Microbial Physiology, v. 23, n. 7, p. 79-150, 1982.

Extracellular polysaccharide. In: REHM, H. J.; REED, G. (Ed.). Biotechnology. Weinheim: Verlag Chemie, 1983. v. 3, p. 531-574.

The role of acylation in exopolysaccharides including those for food use. Food Biotechnology, v. 6, n. 1, p. 75-86, 1992.

VASHITZ, O.; SHEINTUCH, M. Analysis of polymer synthesis rates during steady-state growth of $X$. campestris. Biotechnology and Bioengineerin, v. 37, n. 4, p. 383-385, 1991.

XUEWU, Z. et al. Rheological models for xanthan gum. Journal of Food Engineering, v. 27, p. 203-209, 1996. 